\title{
Vertical Mergers in a Model of Upstream Monopoly and Incomplete Information
}

\author{
Serge Moresi \\ Charles River Associates (CRA), smoresi@crai.com \\ David Reitman \\ Charles River Associates (CRA) \\ Steven C. Salop \\ Georgetown University Law Center, salop@law.georgetown.edu \\ Yianis Sarafidis \\ Charles River Associates (CRA)
}

This paper can be downloaded free of charge from:

https://scholarship.law.georgetown.edu/facpub/2403

https://ssrn.com/abstract=3865093

Forthcoming in Review of Industrial Organization, Special Issue: The U.S. Vertical Merger Guidelines.

This open-access article is brought to you by the Georgetown Law Library. Posted with permission of the author. Follow this and additional works at: https://scholarship.law.georgetown.edu/facpub

Part of the Antitrust and Trade Regulation Commons, Business Organizations Law Commons, Corporate Finance Commons, Law and Economics Commons, and the Securities Law Commons 


\title{
Vertical Mergers in a Model of Upstream Monopoly and Incomplete Information
}

\author{
Serge Moresi, David Reitman, Steven C. Salop, and Yianis Sarafidis*
}

First Draft: June 11, 2021

Revised: August 4, 2021

Forthcoming in Review of Industrial Organization, Special Issue: The U.S. Vertical Merger Guidelines

\begin{abstract}
We examine the role of private information on the impact of vertical mergers. A vertical merger can improve the information that is available to an upstream monopolist because, after the merger, the monopolist can observe the cost of its downstream merger partner. In the pre-merger world, because the costs of the downstream firms are private information, the monopolist has incomplete information and cannot implement the monopoly outcome: The expected pre-merger equilibrium price of the downstream product is lower than the monopoly price. After a vertical merger, the equilibrium input price that is charged to the downstream rival can either increase or decrease -- depending on whether the downstream merger partner's cost is low or high, respectively. However, in all cases the equilibrium price of the downstream product increases to the monopoly price. Therefore, the merger leads to consumer harm even when it leads to a reduction in the input price. The merged firm, however, cannot extract all of the monopoly profit: The merger causes production inefficiency (when the downstream rival has a relatively small cost advantage) and the downstream rival still earns an information rent (when it has a relatively large cost advantage). These results also have implications for vertical merger policy.

JEL Classification: L1, L12, L4, L41, L42
\end{abstract}

Keywords: Vertical Mergers, Monopoly, Foreclosure, Incomplete Information, Antitrust

\footnotetext{
${ }^{*}$ Moresi, Reitman, and Sarafidis are Vice Presidents, Charles River Associates (CRA), Washington, DC. Salop is Professor of Economics and Law, Georgetown University Law Center, and Senior Consultant, CRA. The views expressed herein are those of the authors and do not represent or reflect the views of CRA or any of the organizations with which the authors are affiliated. The authors received financial support from Raytheon Technologies on an earlier version of this article.
} 


\section{Introduction}

The analysis of a vertical merger by an upstream monopolist has a long history and a prominent role in antitrust analysis. Some important themes and developments include:

- The seminal tying model of Burstein (1960) -- which was motivated by Bowman (1957) -- showed that a requirement by a monopolist in one product that buyers also purchase a second product that is currently produced by the monopolist and other (perfectly competitive) firms that sell perfect substitute products with constant marginal cost would have no effect on prices, output, or profits. This result became the famous "single monopoly profit" theorem, as first noted by Bowman (1957) and then popularized by Robert Bork (1978) as a reason to have very permissive antitrust policy towards vertical mergers and other vertical restraints.

- Cournot (1838) showed that the merger of two complementary products monopolists would lead to lower prices -- a result that was applied to vertical mergers by Spengler (1950). This result became the famous "elimination of double marginalization" efficiency benefit of vertical mergers that involve markets where prices exceed marginal costs at both levels.

- When an upstream monopolist that uses linear prices for the input that it supplies to a downstream oligopoly merges with one of the downstream firms, the merged firm benefits from the elimination of double marginalization but may foreclose downstream rivals, completely or partially, from access to the input. Lu, Moresi, and Salop (2007) showed that foreclosure does not occur and the merger is procompetitive if downstream firms face linear demand functions that satisfy Slutsky symmetry. More recently, Das Varma and De Stefano (2020) and Domnenko and Sibley (2020) have studied how partial foreclosure (or raising rivals' costs) can occur if downstream firms face logit demand. They showed that the unintegrated firm often increases its price, which leads to harm to its pre-merger customers who do not switch to the merged firm, and to some that do switch. Das Varma and De Stefano (2020) and Moresi (2020) showed that a vertical merger can reduce consumer surplus and thus be anticompetitive if downstream firms have some bargaining power.

- In a model with non-linear pricing, Hart and Tirole (1990) showed that a vertical merger can solve the upstream monopolist's “commitment" or "opportunism" problem, and lead to lower output and higher prices. 
- Moresi and Schwartz (2021) showed that complete or partial foreclosure can occur and the merger can be anticompetitive, if downstream firms can substitute (imperfectly) the input of the monopolist with an input that is supplied by a fringe of competitive producers.

- When there is not an upstream monopolist, vertical mergers may lead to higher profits and higher prices. Ordover, Saloner, and Salop (1990) showed that a vertical merger by one upstream duopolist can result in higher downstream prices by inducing the other input duopolist to raise its (linear) input price.

- Chen (2001) showed that the competitive effects of a vertical merger depend on the cost of switching suppliers and the degree of downstream product differentiation.

- Rey and Vergé (2020) considered a model with endogenous supply relationships, nonlinear pricing, and secret contracts, and showed that a vertical merger reduces consumer welfare in most cases.

All these models assume that firms have complete information about the production costs of other firms. There is no private information.

In this paper, we examine the role of private information on the effect of vertical mergers when there is an upstream monopolist. We show that a vertical merger can improve the information that is available to an upstream monopolist because, after the merger, the monopolist can observe the cost of its downstream merger partner. In our model, downstream costs are independent, and thus the merger does not reveal any information about the cost of the downstream rival. Because the input monopolist does not have complete information, it cannot implement the monopoly outcome: The expected pre-merger equilibrium price of the downstream product is lower than the monopoly price. After a vertical merger, the equilibrium price increases to the monopoly price, and thus the merger leads to consumer harm. However, the merged firm cannot extract all of the potential profit: The merger causes production inefficiency when the downstream rival has a small cost advantage, and the downstream rival earns an information rent when it has a large cost advantage.

To demonstrate these results most simply, we analyze a model in which a buyer -- who buys from one of two downstream perfect competitors -- purchases one unit if the price does not exceed the buyer's willingness-to-pay, which we refer to as the buyer's "budget". Thus, demand is perfectly inelastic. The output of the upstream monopolist is an input for the downstream firms, which use that input with other inputs in 1-to-1 fixed proportions to produce the two downstream products. These downstream products are perfect substitutes for one another. Except for private information, these are the standard assumptions that are used to establish the single monopoly profit result. 
We assume that the downstream firms purchase the input from the upstream monopolist at prices that are set by the monopolist; the downstream firms then compete for the sale to the buyer through an open-bid descending-price auction. ${ }^{1}$ We model the incomplete information by assuming that the downstream firms each draw their costs independently from a common distribution, and their draws are private information. For simplicity, we assume that the buyer does not use a reserve price and thus starts the descending-price auction with an initial price equal to her budget, and that the input monopolist knows her budget when it sets the input price. ${ }^{2}$

In this structure, if the downstream firms' costs were public information, the single-monopoly-profit result would hold. Absent vertical integration, the upstream monopolist would set an input price such that the total cost of the most efficient of the two downstream firms would equal the buyer's budget. The downstream firms would earn zero profits; all the profits would accrue to the monopolist. The buyer would have zero surplus. Thus, a vertical merger would have no impact on the market prices and welfare. The vertically integrated monopolist would not foreclose the downstream rival: When the rival has lower costs, it is more efficient; the monopolist makes more profit by selling to the rival, letting the rival win the auction, and capturing all rents through the input price.

However, the results change dramatically when the downstream firms' costs are private information. In the pre-merger world, the upstream monopolist is not able to set perfectly discriminating input prices. In this structure, the upstream firm sets an input price to maximize its expected profits. If the downstream firms both draw high costs, then once the input price is included, neither will be able to bid a price at or below the buyer's budget, and so no transaction will occur. If instead both downstream firms draw low costs, they both will bid below the buyer's budget, and the buyer will obtain some surplus.

The vertical merger changes the structure by providing the upstream monopolist with knowledge of the costs of its merger partner. This allows the monopolist to raise the input price to the downstream rival when the monopolist knows that the merger partner has a low cost, and conversely to reduce the input price when the merger partner has a high cost. As it turns out, the buyer always pays the monopoly price whenever the auction generates a sale. However, the merged firm does not obtain all the monopoly profit because the downstream rival still wins the auction and earns some profits when it has a relatively large cost advantage.

\footnotetext{
${ }^{1}$ Our main results do not change if instead the buyer uses a sealed-bid first-price auction.

${ }^{2}$ We discuss those assumptions in Section 5.
} 
The remainder of this paper is organized as follows: Section 2 describes the model, and Section 3 analyzes the pre-merger equilibrium. Section 4 analyzes the post-merger equilibrium, and Section 5 discusses some possible extensions of the model. Section 6 concludes with some implications for vertical merger policy. The Appendix contains the proofs of Propositions 2 and 3.

\section{Model description}

Consider an upstream monopolist - $\mathrm{U}$-- that supplies a necessary input to two downstream competitors, D1 and D2. The downstream firms are ex ante symmetric and use the input to make identical output in a 1-to-1 proportion. They then compete in an auction setting to sell their output to a single buyer. We assume that the quantity of output or product demanded by the buyer is fixed at one unit.

Let $c$ denote the cost that is incurred by $\mathrm{U}$ for producing the input. Given the assumed symmetry, $\mathrm{U}$ sets the same input price $W$ to both $\mathrm{D} 1$ and $\mathrm{D} 2$. We assume that $\mathrm{D} 1$ and $\mathrm{D} 2$ observe $W$ at the time that they bid in the buyer's auction, and only the downstream firm that wins the auction will purchase U's input.

The downstream firm that wins the auction will combine U's input with other inputs to produce the output. The cost that a downstream firm will incur for those other inputs (should the firm win the auction) is private information known only by that firm. Formally, the costs of the downstream firms' inputs are random variables and are drawn independently for each of the two firms from a common distribution. D1 and D2 draw costs $C_{1}$ and $C_{2}$, respectively, which gives the two firms total costs of $W+C_{1}$ and $W+C_{2}$, respectively, for supplying the output to the buyer.

The buyer values the product at $V$, which is known to all participants and is the same for the output of both D1 and D2. The buyer purchases the product from either D1 or D2 with the use of an open-bid descending-price auction having the following structure:

- The auction price begins at $V$; as long as both D1 and D2 elect to participate, the price descends gradually until one of the two firms drops out, at which time the auction ends. The remaining firm wins the contract, and the purchase price that is paid by the buyer is the price at which the other firm dropped out.

- If only one firm elects to participate in the auction at price $V$, then the auction ends immediately, that firm wins the contract, and the purchase price paid by the buyer is equal to $V$.

- If no firms elect to participate in the auction at price $V$, then no purchase takes place. 
A seminal article by Vickrey (1961) established two well-known results:

(1) A seller's dominant strategy is to (a) participate in the auction as long as the price is above the seller's total cost of supplying the product; and (b) drop out from the auction as soon as the price reaches the seller's total cost of supplying the product. ${ }^{3}$

(2) The open-bid descending-price auction is equivalent to the sealed-bid second-price auction. ${ }^{4}$

Using the language of a second-price auction, we refer to the price at which a firm will drop out of the descending-price auction as the firm's bid.

Given this setting, we first solve for the pre-merger equilibrium in which U, D1, and D2 are independent profit-maximizing entities. We then solve for the post-merger equilibrium after $\mathrm{U}$ and D1 merge, and refer to the merged firm as UD1.

We make the following assumptions: The downstream costs of D1 and D2 are independently and identically distributed according to a log-concave distribution function $F\left(C_{i}\right)$, with corresponding density function $f\left(C_{i}\right)$. These costs are distributed on the interval $[A, B]$, and $f\left(C_{i}\right)>0$ if and only if $C_{i} \in[A, B]$. The density $f$ is continuously differentiable, and its derivative function $f^{\prime}$ satisfies $f^{2} \geq(1-F) f^{\prime}$. Finally, $V>c+A$ so that there is a positive expected total surplus from producing the product.

\section{Pre-merger equilibrium}

We first discuss the auction outcome as a function of the input price $W$, and then solve for the input price that maximizes U's expected profit given the subsequent auction outcome.

As explained above, each downstream firm bids its total cost. D1 bids $W+C_{1}$, and D2 bids $W+C_{2}$. Therefore, the result of the buyer's auction is that the firm with the lowest cost realization $C_{i}$ wins the auction as long as $\min \left(C_{1}, C_{2}\right)+W \leq V$ and receives a price of $\min \left(\max \left(C_{1}, C_{2}\right)+W, V\right)$.

\footnotetext{
${ }^{3}$ Intuitively, dropping out before the price reaches one's cost yields zero profit, while continuing to participate yields a positive profit if the other bidder is about to drop out; and continuing to participate when the price falls below one's cost yields a negative profit if one wins.

${ }^{4}$ Intuitively, the buyer asks each seller to submit, in a sealed envelope, the price at which the seller wants to drop out. The buyer then opens the two envelopes, selects the seller with the lowest bid as the winner, and pays to the winner a price equal to the bid of the other seller. This "replicates" the descending-price auction, and thus bidding at cost is the dominant strategy for each seller.
} 
If total costs for both D1 and D2 are sufficiently high, then neither firm participates in the auction, and the buyer does not purchase the product. Given the dominant bidding strategy, D1 will not participate in the auction if $W+C_{1}>V$, which occurs with probability $1-F(V-W)$. The probability that $\mathrm{D} 2$ will not participate is the same. Therefore, the probability that neither firm participates in the auction and no sale is made is $[1-F(V-W)]^{2}$.

With regard to the upstream firm $U$, its expected profits as a function of the input price are equal to the margin that is earned on the input multiplied by the probability that the auction concludes with a sale, or

$$
\Pi_{U}=(W-c)\left\{1-[1-F(V-W)]^{2}\right\}
$$

Note that $\Pi_{U}=0$ if $\mathrm{U}$ sells the input at cost, $W=c$, or if $\mathrm{U}$ sets a very high input price, $W \geq V-A$. Therefore, the profit-maximizing input price -- which is denoted by $W^{*}--$ is greater than $c$ and smaller than $V-A$.

Proposition 1. The pre-merger equilibrium input price, $W^{*}$, satisfies

$$
W^{*}=c+\left[\frac{1}{2} \frac{2-F\left(V-W^{*}\right)}{1-F\left(V-W^{*}\right)}\right] \frac{F\left(V-W^{*}\right)}{f\left(V-W^{*}\right)}>V-B
$$

Proof. The first-order condition is

$$
\frac{d \Pi_{U}}{d W}=1-[1-F(V-W)]\{1-F(V-W)+2(W-c) f(V-W)\}=0 .
$$

If $W \leq V-B$, then $\frac{d \Pi_{U}}{d W}=1>0$; and if $W=V-A$, then $\frac{d \Pi_{U}}{d W}=-2(V-A-c) f(A)<0$. Therefore, $W^{*} \in(V-B, V-A) . \Pi_{U}$ is strictly concave in $W$ for all $W \in(V-B, V-A)$.

Proposition 1 shows that $W^{*}>V-B$ and, therefore, the pre-merger equilibrium outcome is such that there is a strictly positive probability that D1 and D2 will not participate in the buyer's auction: In equilibrium $U$ always sets the input price sufficiently high so that the probability that there will be no sale at the auction, $\left[1-F\left(V-W^{*}\right)\right]^{2}$, is strictly positive. Proposition 1 also shows that $W^{*}<V-A$ and thus the probability that there will be a sale at the auction is strictly positive.

Figure 1 below illustrates the pre-merger equilibrium outcome. If only one firm has downstream costs that are less than $V-W^{*}$, then that firm wins and the sale price is $V$. If both have costs below $V-W^{*}$, then the firm with lowest cost wins at a price below $V$ (equal to the total cost of the other firm). And if neither firm has costs below $V-W^{*}$, then there is no sale. 
Figure 1: Outcomes of the Pre-Merger Auction

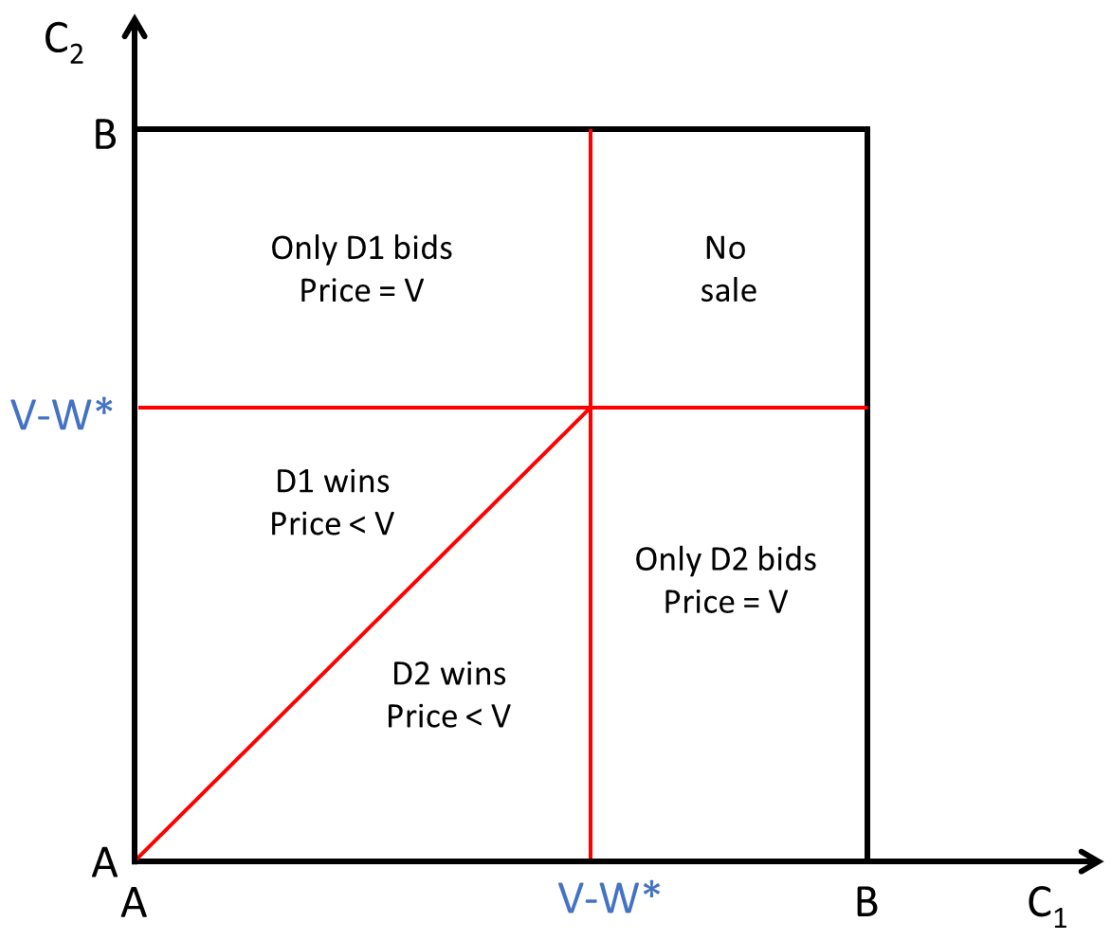

In the case in which costs are uniformly distributed, the above first-order condition reduces to

$$
(B-A)^{2}-(B-V+W)\{B-V+W+2(W-c)\}=0 .
$$

This is a quadratic equation in $W$, and the solution that maximizes U's expected profit is ${ }^{5}$

$$
W^{*}=\frac{2 V-2 B+c+\sqrt{(V-B-c)^{2}+3(B-A)^{2}}}{3} .
$$

One can check that $V-W^{*}<B$ and hence the probability of no sale is strictly positive. Since we assume $V-A-c>0$, one can check that $V-W^{*}>A$ and hence the probability of a sale is strictly positive.

The main results obtained in this section also would apply if one assumed that the buyer uses a sealed-bid first-price auction with a reserve price equal to $V$, instead of an open-bid descending-price auction with

\footnotetext{
${ }^{5}$ The other solution of the quadratic equation does not satisfy $W \in(V-B, V-A)$.
} 
starting price equal to $V$. The pre-merger equilibrium input price and probability of a sale is the same for either type of auction, ${ }^{6}$ and the expected price paid by the buyer does not change either. ${ }^{7}$

\section{Post-merger equilibrium}

The structure of the model for the post-merger equilibrium is similar: UD1 first sets the input price - $W$-that it will charge to D2 if D2 wins the auction. Knowing that price, UD1 and D2 compete in the auction, which has the same design as pre-merger. We assume that UD1 knows its downstream cost realization $C_{1}$ at the time that it sets $W$.

To find the post-merger equilibrium, we start once again with the solution to the auction once each firm knows its own downstream costs and $W$ has been set. For D2, the optimal strategy is unchanged: It is still a dominant strategy to bid its total cost of supplying the product, which is $W+C_{2}$, or to not participate in the auction if $W+C_{2}>V$.

The optimal bidding strategy for UD1 is different from that of D1 pre-merger. First, since the relevant input cost to UD1 is not $W$ but $c$, UD1 participates in the auction if and only if $c+C_{1} \leq V$. Second, if both UD1 and D2 participate, then UD1's optimal bidding strategy takes into account the impact of variations in its bid on both upstream and downstream profits. There are two offsetting effects from vertical integration: One is elimination of double marginalization, since the input cost to UD1 is $c$, which is lower than the pre-merger input price $W^{*}$; this puts downward pressure on UD1's bid in the auction. The other effect is that, if UD1 raises its bid and loses, UD1 recaptures some of the lost profit by selling the input to D2. This puts upward pressure on UD1's bid.

These two effects offset exactly, and the merged firm uses the same bidding strategy as D2: It bids $W+$ $C_{1}$. In effect, the merged firm treats the profit from an input sale to $\mathrm{D} 2, W-c$, as an opportunity cost and

\footnotetext{
${ }^{6}$ Given our assumption that D1 and D2 draw their costs $C_{1}$ and $C_{2}$ from the same distribution, D1 and D2 use the same bid function $b(\cdot)$, i.e., their bids are $b\left(W+C_{1}\right)$ and $b\left(W+C_{2}\right)$, respectively. While the bid function in the first-price auction is different from that in the descending-price auction, both are strictly monotonic and satisfy $b(V)=V$. It follows that the probability that a downstream firm participates in the auction is the same for both types of auction, and hence U's profit function and the optimal input price are also the same.

${ }^{7}$ In the auction literature, this result is known as the Revenue Equivalence Theorem. For any given realization of the (independent) cost draws, the first-price auction and the descending-price auction lead to different prices; however, across all possible realizations, the expected or average price is the same for both types of auction.
} 
bids $c+(W-c)+C_{1}=W+C_{1} \cdot{ }^{8}$ (This implicitly assumes $W+C_{1} \leq V$. If instead $W+C_{1}>V$, then UD1 bids $V$.)

The optimal input price -- $\widehat{W}$-- that UD1 charges to D2 post-merger depends on whether downstream production by UD1 is viable or not viable: whether $C_{1}+c \leq V$ versus $C_{1}+c>V$, respectively.

Proposition 2. (i) If downstream production by UD1 is not viable (if $C_{1}>V-c$ ) then UD1 does not participate in the auction, and $\widehat{W}$ satisfies

$$
\widehat{W}=c+\frac{F(V-\widehat{W})}{f(V-\widehat{W})} .
$$

If $C_{2} \leq V-\widehat{W}$, then $\mathrm{D} 2$ participates and wins the auction at price $V$; otherwise, there is no sale.

(ii) If instead downstream production by UD1 is viable (if $C_{1} \leq V-c$ ) then UD1 participates in the auction. The input price that is charged by UD1 to D2 is a function $\widehat{W}\left(C_{1}\right)$ that depends on UD1's downstream $\operatorname{cost} C_{1} \cdot \widehat{W}\left(C_{1}\right)$ satisfies:

$$
\widehat{W}\left(C_{1}\right)=V-C_{1}+\frac{F\left(V-\widehat{W}\left(C_{1}\right)\right)}{f\left(V-\widehat{W}\left(C_{1}\right)\right)} .
$$

UD1 bids $V .{ }^{9}$ If $C_{2} \leq V-\widehat{W}\left(C_{1}\right)$, then D2 participates and wins at price $V$ because UD1 immediately drops out; otherwise, D2 does not participate, and UD1 wins at price $V$.

Proof. See Appendix.

Proposition 2 has several interesting implications: First, whenever there is a successful sale in the auction, the price that is paid by the buyer post-merger is always equal to $V$. Thus, the buyer's surplus is always

\footnotetext{
${ }^{8}$ The optimality of bidding $W+C_{1}$ can be checked by considering UD1's decision of whether to drop out of the auction or not, as the price descends gradually. If UD1 drops out when the price is $P$, it will earn a profit of $W-c$ by supplying the input to D2. If instead UD1 does not drop out, UD1 can win the auction and earn a profit that is equal to $P-c-C_{1}$ if D2 drops out in this bidding round; if D2 does not drop out, then UD1 has the option of dropping out in the next round when the buyer will reduce the price by another (small) increment. It follows that UD1 will drop out as soon as the price reaches the point where UD1's profit from winning, $P-c-C_{1}$, is equal to its profit from losing: $W-c$. That happens when $P=W+C_{1}$.

${ }^{9} \mathrm{UD} 1$ is still following the downstream dominant strategy of bidding the minimum of $V$ and its own costs (including the opportunity cost). But the function $\widehat{W}\left(C_{1}\right)$ is such that $\widehat{W}\left(C_{1}\right)+C_{1}>V$, so the optimal downstream strategy is to bid $V$.
} 
zero post-merger, while the buyer's expected surplus is always strictly positive pre-merger. The merger, therefore, is anticompetitive.

Second, when downstream production by UD1 is viable, the input price $\widehat{W}\left(C_{1}\right)$ that is charged by UD1 to D2 is higher when UD1's cost $C_{1}$ is lower. Intuitively, when UD1's cost is lower, UD1 will earn a higher profit if it supplies the product to the buyer, and thus UD1 increases the input price -- so as to let D2 enter and win the auction only when D2 will have an even greater cost advantage. The expected profits for UD1 from this strategy are greater than the profits from completely foreclosing D2.

Third, complete foreclosure never occurs in this model. By not completely excluding D2, UD1 is able to increase profits in two ways: When UD1 draws high costs, to the point that the value of the product is below UD1's costs, UD1 is able to make an upstream sale when D2 draws relatively low costs. And even when downstream production by UD1 is viable, UD1 increases its profits by charging a high input price and letting D2 win the auction when D2 has sufficiently low costs. In this way, UD1 takes advantage of the efficiency of D2 and extracts some of the efficiency gains.

Figure 2: Outcomes of the Post-Merger Auction (when $V<c+B$ )

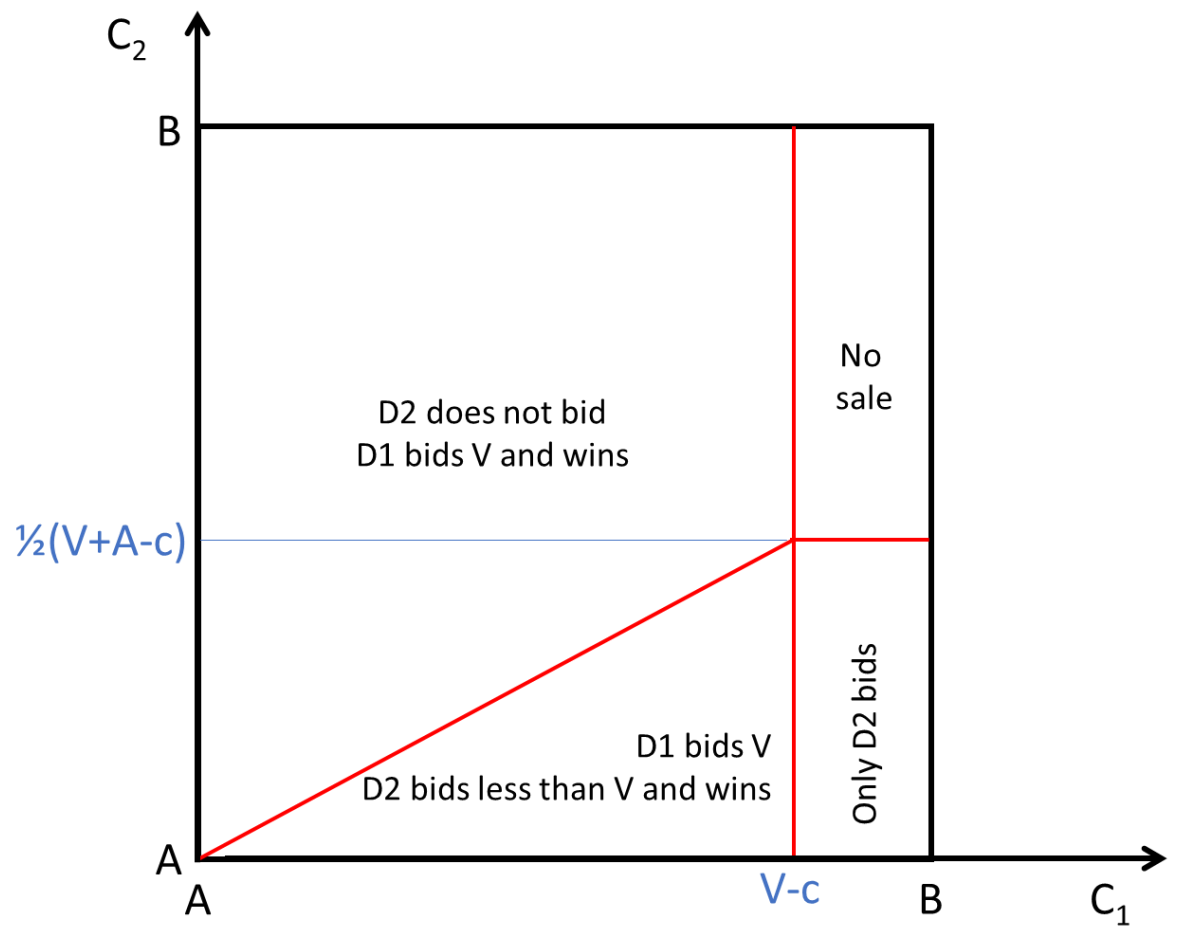


The post-merger outcomes that are described in Proposition 2 are shown in Figure 2 (which assumes that downstream costs are uniformly distributed). ${ }^{10}$ Downstream production by UD1 is not viable when $C_{1}>$ $V-c$, in which case UD1 sets $\widehat{W}=(V-A+c) / 2$ and D2 bids if $C_{2} \leq(V+A-c) / 2$. When $C_{1} \leq$ $V-c$, downstream production by UD1 is viable, the input price is $\widehat{W}\left(C_{1}\right)=V-\left(A+C_{1}\right) / 2$, and D2 bids if $C_{2} \leq \frac{1}{2}\left(A+C_{1}\right)$.

Again, the above results also apply if one assumes that the buyer uses a first-price auction instead of a descending-price auction. For either type of auction, the post-merger equilibrium input price and probability of a sale are the same, ${ }^{11}$ and the price paid by the buyer (when there is a sale) is equal to $V$. Similarly, the next results also apply regardless of which of the two auction designs the buyer uses.

Proposition 3. (i) If downstream production by UD1 is not viable, then $\widehat{W}<W^{*}$.

(ii) If instead downstream production by UD1 is viable, then $\widehat{W}\left(C_{1}\right)>W^{*}$ if $C_{1}$ is sufficiently low.

Proof. See Appendix.

The first part of Proposition 3 shows that partial foreclosure does not occur if downstream production by $\mathrm{UD} 1$ is not viable. When the merged firm has a high $\operatorname{cost} C_{1}$ and cannot profitably supply the product to the buyer, it offers the input to D2 at a lower price than pre-merger $\left(\widehat{W}<W^{*}\right)$. The second part of Proposition 3 shows that partial foreclosure occurs when the merged firm can profitably supply the product and has a low cost $C_{1} \cdot{ }^{12}$

\section{Extensions}

We conclude with a few remarks on possible extensions and variants of the model. We also offer conjectures as to some results based on our intuition and continuing research.

We have focused on the most pristine version of the model in which the buyer demands a single unit, the buyer's budget is known, and the buyer does not set a reserve price. If these assumptions are relaxed, the analysis becomes more complex. However, we do not think that our basic results on the effects of a

\footnotetext{
${ }^{10}$ If the buyer's budget is relatively large, with $V \geq c+B$, then downstream production by UD1 is always viable, and thus only the second part of Proposition 2 applies. Figure 2 assumes that $V<c+B$, so that downstream production by UD1 can be either viable or not viable.

${ }^{11}$ The proof is provided in the Appendix.

${ }^{12}$ When costs are uniformly distributed, partial foreclosure occurs when $C_{1}<2\left(V-W^{*}\right)-A$.
} 
vertical merger will change if these assumptions are relaxed. The single monopoly profit theorem is unlikely to obtain in a general way -- because of incomplete information.

Our model assumed that the merged firm knows the cost realization $C_{1}$ of its downstream affiliate at the time that it sets the input price $W$ to the downstream rival. This assumption likely will be satisfied in many cases. However, if instead the merged firm must set $W$ before learning the realization of $C_{1}$, the merger still leads (on average) to an increase in downstream prices and a reduction in consumer welfare.

The post-merger equilibrium resembles the pre-merger equilibrium in that the merged firm sets an input price that is above marginal cost; and if both downstream firms have cost realizations such that $W+C_{i}<$ $V$, then the most efficient firm wins the auction at a price that is below $V$. (By contrast, the post-merger price in our model is never below $V$, and the downstream rival does not always win when it is the most efficient firm.) However, for this variant (where the merged firm does not know $C_{1}$ when it sets the input price $W$ post-merger) the merged firm sets $W$ above the pre-merger level $W^{*}$, which results (on average) in higher downstream prices and reduced consumer welfare..$^{13}$

Our model also assumes that the buyer's budget $V$ is known to the firms. If instead $V$ is unknown to the firms, the buyer in a way will reveal it to D1 and D2 at the beginning of the descending-price auction. ${ }^{14}$ Pre-merger, $\mathrm{U}$ takes the uncertainty about $V$ into account when setting the input price $W$, and the outcome of the auction is similar to when $V$ is known: There is a probability of no sale (which is high when $V$ turns out to be low), and the buyer obtains a surplus (which is high when $V$ turns out to be high). Post-merger, $\mathrm{U}$ will still have more information (it will know $C_{1}$ ) and thus will charge an input price to $\mathrm{D} 2$ that takes this information into account. Thus, we conjecture that post-merger the buyer will pay a higher price.

Our model further assumes that the buyer does not set a reserve price: The buyer starts the descendingprice auction with an initial price that is equal to her budget $V$. If instead the buyer can set a reserve price and change it after the merger, then the buyer may be able to mitigate the harm from the merger. In the

\footnotetext{
${ }^{13}$ Intuitively, whereas pre-merger an increase in $W$ above $W^{*}$ resulted in the loss of marginal sales regardless of which downstream firm was more efficient, post-merger the merged firm no longer loses those sales when D1 is more efficient, since with the elimination of double marginalization it can still profitably sell at price $V$. At the optimal $\widehat{W}$ : the range of cost realizations where the buyer receives no surplus expands; the region where the price is below $V$ shrinks; and the downstream price that results from the auction is higher at every point in that region. Thus, consumer surplus falls. D2 still receives some sales and profits when it is more efficient. Details are available upon request.

${ }^{14}$ If the buyer uses a reserve price, she will start the auction at a price below her budget. In any event, the bidding strategies of D1 and D2 are not affected.
} 
context of horizontal mergers, Waehrer and Perry (2003) find that by adjusting the reserve price in an optimal way, the buyer may be able to mitigate the merger's adverse price effects. However, the envelope theorem implies that the merger still reduces the buyer's surplus: Adjusting the reserve price has only a "second-order effect"; therefore, the qualitative results that are obtained with the assumption of a fixed reserve price are likely to be robust. While we are studying vertical mergers, we expect that the envelope theorem would apply similarly here.

\section{Implications for Vertical Merger Policy}

The results of this model of a monopolist in one market (protected by prohibitive entry barriers) and duopoly competition in the other market can have significant implications for vertical merger policy. The single monopoly profit theory still remains embedded in the thinking of many economists and enforcers. By contrast, even while retaining a number of the assumptions analogous to those in the Bowman (1957) model (i.e., homogeneous products, inelastic consumer demand, and a second price auction), our model finds that vertical mergers involving monopolists at the upstream level are not competitively neutral. Nor are they procompetitive. Instead, when the production costs of the downstream firms are private information, such mergers are systematically anticompetitive. This both rebuts the single monopoly profit theory and a presumption that such mergers are either procompetitive or neutral.

The model and the results are straightforward. The presence of private information leads to consumers sometimes obtaining prices below their reservation prices in the pre-merger world. While the merger leads to more transactions, consumers themselves are harmed by now always having to pay the full monopoly price, despite a type of internalization of double marginalization. Thus, our model suggests that vertical mergers involving a monopolist should not be ignored by antitrust authorities. To the contrary, they should be analyzed with considerable skepticism.

Our model thus complements the Bertrand and bargaining models analyzed by Domnenko and Sibley (2020) and Das Varma and De Stefano (2020). Those models also show that vertical mergers involving a monopolist at one level are not neutral, and instead harm consumers in some (but not all) circumstances. Their price and welfare results depend on the structure of product differentiation, the shape of the demand curve, the firms' costs, and the bargaining power of downstream firms. Thus, those models also refute the claim that vertical mergers involving a protected monopolist can be presumed to be procompetitive, or neutral at worse. In those models, however, whether consumers are benefited or harmed depends on the facts, which thus must be analyzed in detail. That said, the models make it clear that merger-specific elimination of double marginalization may not be sufficient to offset vertical foreclosure effects and thus 
cause an increase in overall consumer welfare. They further emphasize the fact that, when downstream firms sell differentiated products, the consumers who purchase the product of the merged firm may benefit from lower prices, but the consumers who purchase the product of the unintegrated firm may be harmed from higher prices. In fact, this is the empirical finding of Luco and Marshall (2020).

\section{References}

Blair, R.D. \& Kaserman, D.L. (1978). Vertical Integration, Tying, and Antitrust Policy. American Economic Review 68(3), 397-402.

Bork, R.H. (1978). The Antitrust Paradox. New York: Basic Books.

Bowman, W.S. (1957). Tying Arrangements and the Leverage Problem. Yale Law Journal 67(1), 19-36.

Burstein, M.L. (1960). The Economics of Tie-in Sales. Review of Economics and Statistics 42(1), 68-73.

Chen, Y. (2001). On Vertical Mergers and Competitive Effects. The RAND Journal of Economics 32(4), 667-685.

Cournot, A.A. (1838). Mathematical Principles of the Theory of Wealth (pp. 99-117). Reprinted New York: Augustus M. Kelley (1971).

Das Varma, G. \& De Stefano, M. (2020). Equilibrium Analysis of Mergers. The Antitrust Bulletin 65(3), 445-458.

Domnenko, G. \& Sibley, D.S. (2020). Simulating Vertical Mergers and the Vertical GUPPI Approach. Mimeo. Available at http://dx.doi.org/10.2139/ssrn.3606641.

Hart, O. \& Tirole, J. (1990). Vertical Integration and Market Foreclosure. Brookings Papers on Economic Activity Washington: Brookings Institution, 205-286.

Lu, S., Moresi, S., \& Salop, S.C. (2007). A Note on Vertical Mergers with an Upstream Monopolist: Foreclosure and Consumer Welfare Effects. Mimeo. Available at https://www.crai.com/sites/default/files/publications/Merging-with-an-upstream-monopolist.pdf.

Luco, F. \& Marshall, G. (2020). The Competitive Impact of Vertical Integration by Multiproduct Firms. American Economic Review 110(7), 2041-2064. 
Moresi, S. (2020). Vertical Mergers and Bargaining Models: Simultaneous versus Sequential Pricing. Available at https://papers.ssrn.com/sol3/papers.cfm?abstract_id=3541099.

Moresi, S. \& Schwartz, M. (2021). Vertical Mergers with Input Substitution: Double Marginalization, Foreclosure and Welfare. Economics Letters 202.

Ordover, J.A., Saloner, G., \& Salop, S.C. (1990). Equilibrium Vertical Foreclosure. American Economic Review 80(1), 127-142.

Rey, P., \& Vergé, T. (2020). Multilateral vertical contracting. Retrieved from https://www.tsefr.eu/sites/default/files/TSE/documents/doc/by/rey/744 version2020.pdf.

Spengler, J.J. (1950). Vertical Integration and Antitrust Policy. Journal of Political Economy 58(4), 347352.

Waehrer, K., \& Perry, M.K. (2003). The Effects of Mergers in Open-Auction Markets. The RAND Journal of Economics 34(2), 287-304.

Vickrey, W. (1961). Counterspeculation, Auctions, and Competitive Sealed Tenders. Journal of Finance $16(1), 8-37$.

\section{Appendix}

\section{Proof of Proposition 2}

We begin with the case when downstream production by UD1 is not viable: $c+C_{1}>V$. UD1 participates in the market only as a supplier to D2 and sets $W$ to maximize upstream expected profits. Those profits are given by $(W-c) F(V-W)$, are strictly increasing in $W$ at $W=c$, and are strictly decreasing in $W$ at $W=V-A$. Thus, the optimal input price $\widehat{W} \in(c, V-A)$. Since $F$ is log-concave, profits are strictly quasi-concave in $W$ for all $W \in(c, V-A)$. From the first-order condition, $\widehat{W}$ satisfies

$$
\widehat{W}=c+\frac{F(V-\widehat{W})}{f(V-\widehat{W})}
$$

When costs are uniformly distributed, $\widehat{W}=\frac{1}{2}(V-A+c)$.

To summarize, when $C_{1}>V-c$, downstream production by UD1 is not viable, UD1 sets the input price $\widehat{W}$ given by (A1), UD1 does not participate in the auction, and either D2 participates and wins (if $C_{2} \leq$ 
$V-\widehat{W}$ ), in which case the buyer pays $V$ to $\mathrm{D} 2$, or D2 does not participate (if $C_{2}>V-\widehat{W}$ ), in which case there is no sale.

We now turn to the case when downstream production by UD1 is viable: $c+C_{1} \leq V$. It is helpful to partition the range of possible values for $W$ into three regions:

\section{Region 1: $W>V-A$}

If $W$ is in this region, even the most efficient type of $\mathrm{D} 2$ would not bid, since $W+A>V$. This is in effect an exclusionary strategy by UD1, where it is the only bidder in the auction. Without competition, UD1 always bids $V$. Therefore, expected profit from an exclusionary input price strategy is $V-C_{1}-c$.

Region 2: $V-C_{1} \leq W \leq V-A$

Since $V<C_{1}+W$ for $W$ in (the interior of) this region, if D2 participates in the auction, then UD1 is better off letting D2 win, since the gains from losing and only supplying the input, which are $W-c$, are larger than the gains from winning at price $V$, which are $V-C_{1}-c .{ }^{15}$ If instead D2 does not participate, then UD1 maximizes its profit by bidding $V$ and earning $V-C_{1}-c$. Thus, in Region 2 the optimal downstream bid of UD1 is $V$.

Given this auction strategy, it remains to determine what wholesale price within Region 2 is optimal and what is UD1's (expected) profit at that price. Profits for UD1 in Region 2 are

$$
\Pi(W)=F(V-W)(W-c)+[1-F(V-W)]\left(V-C_{1}-c\right)
$$

The first-order condition is

$$
\frac{d \Pi}{d W}=-\left(W+C_{1}-V\right) f(V-W)+F(V-W)=0
$$

Note that when $W=V-C_{1}, \Pi=V-C_{1}-c$ and $\frac{d \Pi}{d W}=F\left(\mathrm{C}_{1}\right)>0$; while at the other end of the region when $W=V-A, \Pi=V-C_{1}-c$ and $\frac{d \Pi}{d W}=-\left(C_{1}-A\right) f(A)<0 .{ }^{16}$ Thus, UD1 increases profits by

\footnotetext{
${ }^{15} V<C_{1}+W$ implies $V-C_{1}-c<W-c$.

${ }^{16}$ For $C_{1}=A$, we have $F\left(C_{1}\right)=0$ and $-\left(C_{1}-A\right) f(A)=0$, but the argument goes through: UD1 increases profits by picking $W$ in the interior of Region 2 .
} 
picking $W$ in the interior of Region 2, and in so doing earns higher expected profits than $V-C_{1}-c$ and, hence, higher expected profits than it receives from the exclusionary strategy in Region 1.

From the first-order condition, $\widehat{W}$ satisfies

$$
\widehat{W}=V-C_{1}+\frac{F(V-\widehat{W})}{f(V-\widehat{W})}
$$

When costs are uniformly distributed, the solution to the first-order condition is halfway between the two endpoints of Region 2: $\widehat{W}=V-\frac{1}{2}\left(A+C_{1}\right)$. For later use, note that (A2) implies that $\widehat{W}$ is a strictly decreasing function of $C_{1}$ (for $C_{1} \leq V-c$ ).

\section{Region 3: $W<V-C_{1}$}

In this region, UD1's profit if D2 wins is equal to $W-c$ (which is smaller than $V-C_{1}-c$ ) and UD1's profit if it wins is at most equal to $V-C_{1}-c$. Recall that $c+C_{1} \leq V$, and so a sale will be made regardless of the chosen value of $W$. Thus, if UD1 sets $W$ in this region, it earns lower expected profits than if it sets $W$ in Region 2.

To summarize, when $C_{1} \leq V-c$, downstream production by UD1 is viable, UD1 sets the input price $\widehat{W}\left(C_{1}\right)$ given by (A3), UD1 bids $V$, and either D2 participates and wins (if $C_{2}<V-\widehat{W}\left(C_{1}\right)$ ), in which case the buyer pays $V$ to D2, or D2 does not participate and UD1 wins (if $C_{2} \geq V-\widehat{W}\left(C_{1}\right)$ ), in which case the buyer pays $V$ to UD1.

\section{Proof that the main results in Proposition 2 also apply if the buyer uses a first-price auction}

We want to show that the following strategies and beliefs constitute a perfect Bayesian equilibrium:

- If downstream production by UD1 is not viable (if $C_{1}>V-c$ ), UD1 sets the input price equal to $\widehat{W}$ (as given by (A1)), and does not bid. If instead downstream production by UD1 is viable (if $C_{1} \leq V-c$ ), UD1 sets the input price equal to $\widehat{W}\left(C_{1}\right)$ (as given by (A3)), and bids $V$.

- If D2 observes $\widehat{W}, \mathrm{D} 2$ believes that UD1 does not bid, and D2 either bids $V$ or does not bid (depending on whether D2 is viable or not). If D2 observes $\widehat{W}\left(C_{1}\right)>\widehat{W}$, D2 believes that UD1 bids $V$, and $\mathrm{D} 2$ either bids slightly below $V$ or does not bid. If D2 observes an input price either strictly lower than $\widehat{W}$ or strictly higher than $\widehat{W}(A)$, D2 believes that UD1 does not bid, and D2 either bids $V$ or does not bid. 
One can check that (1) given the input price strategy of UD1, D2's beliefs satisfy Bayes rule; (2) given the bid strategy of UD1 and the beliefs of D2, D2's bid strategy is a best response; (3) given UD1's input price strategy and D2's bid strategy, UD1's bid strategy is a best response. Finally, one can check that UD1 has no incentive to deviate and use a different input price strategy.

To see this last point, suppose first that downstream production by UD1 is not viable and, instead of setting the input price equal to $\widehat{W}$, UD1 were to set $W \in(\widehat{W}, \widehat{W}(A)]$. Then, D2 would (wrongly) believe that downstream production by UD1 is viable and that UD1 will bid $V$ (instead of not bidding). Thus, D2 would either bid slightly below $V$ (instead of bidding $V$ ) or not bid if it is not viable to bid. Such deviation would reduce UD1's expected profit because its effect on the probability of a sale is virtually the same as when the buyer uses a descending-price auction (and we know from Proposition 2 that the deviation is not profitable). If instead UD1 were to set $W \notin[\widehat{W}, \widehat{W}(A)]$, D2 would still believe that downstream production by UD1 is not viable, and such deviation also would reduce UD1's expected profit for the same reason.

Suppose now $C_{1}<V-c$ so that downstream production by UD1 is viable, but UD1 sets $W>\widehat{W}(A)$ or $W \leq \widehat{W}$, instead of setting $W=\widehat{W}\left(C_{1}\right)$. Then, D2 would (wrongly) believe that downstream production by UD1 is not viable and that UD1 will not bid (instead of bidding $V$ ). Thus, D2 would either bid $V$ (instead of bidding slightly below $V$ ) or not bid if it is not viable. Such deviation would reduce the expected profit of UD1, because (i) its effect on the probability of a sale would be the same as when the buyer uses a descending-price auction, and (ii) when D2 is viable and $W>V-C_{1}$, UD1 and D2 would tie but UD1 would prefer D2 to win. If instead UD1 were to deviate and set a different price $W \in$ $(\widehat{W}, \widehat{W}(A)]$, D2 would still believe that downstream production by UD1 is viable, and thus such deviation also would reduce UD1's expected profit, as is the case when the buyer uses a descending-price auction.

\section{Proof of Proposition 3}

(i) If downstream production by UD1 is not viable, then $\widehat{W}<W^{*}$.

From the main text, the first-order condition for $W^{*}$ is

$$
\frac{d \Pi_{U}}{d W}=1-\left[1-F\left(V-W^{*}\right)\right]\left\{1-F\left(V-W^{*}\right)+2\left(W^{*}-c\right) f\left(V-W^{*}\right)\right\}=0 .
$$

Rearranging terms, $W^{*}$ satisfies 


$$
F\left(V-W^{*}\right)-\left(W^{*}-c\right) f\left(V-W^{*}\right)=\frac{-F\left(V-W^{*}\right)^{2}}{2\left[1-F\left(V-W^{*}\right)\right]} .
$$

The post-merger first-order condition for $\widehat{W}$ in the case when downstream production by UD1 is not viable $\left(c+C_{1}>V\right)$ is

$$
\frac{d \Pi}{d \widehat{W}}=F(V-\widehat{W})-(\widehat{W}-c) f(V-\widehat{W})=0
$$

Using (A4) to evaluate this first-order condition at $\widehat{W}=W^{*}$,

$$
\left.\frac{d \Pi}{d \widehat{W}}\right|_{\widehat{W}=W^{*}}=\frac{-F\left(V-W^{*}\right)^{2}}{2\left[1-F\left(V-W^{*}\right)\right]}<0 .
$$

Therefore, in this case, the profit-maximizing value of $\widehat{W}$ satisfies $\widehat{W}<W^{*}$.

(ii) If downstream production by UD1 is viable, then $\widehat{W}\left(C_{1}\right)>W^{*}$ if $C_{1}$ is sufficiently low.

Rearranging the first-order condition for $W^{*}$ once again, $W^{*}$ satisfies

$$
f\left(V-W^{*}\right)=\frac{F\left(V-W^{*}\right)}{W^{*}-c}\left[1+\frac{F\left(V-W^{*}\right)}{2\left[1-F\left(V-W^{*}\right)\right]}\right] .
$$

The first-order condition for $\widehat{W}\left(C_{1}\right)$ when downstream production by UD1 is viable is given by (A2). When we evaluate (A2) at $W^{*}$ with the use of (A5),

$$
\left.\frac{d \Pi}{d \widehat{W}}\right|_{\widehat{W}=W^{*}}=F\left(V-W^{*}\right)\left\{1-\left(\frac{W^{*}+C_{1}-V}{W^{*}-c}\right)\left[1+\frac{F\left(V-W^{*}\right)}{2\left[1-F\left(V-W^{*}\right)\right]}\right]\right\} .
$$

As shown in Proposition 1, $W^{*}<V-A$, and so $W^{*}+C_{1}-V<0$ if $C_{1}$ is sufficiently low (sufficiently close to $A)$. Thus, for sufficiently low $C_{1},\left.\frac{d \Pi}{d \widehat{W}}\right|_{\widehat{W}=W^{*}}>0$. Therefore, for sufficiently low $C_{1}, \widehat{W}\left(C_{1}\right)>$ $W^{*}$. 